\title{
EL PRINCIPIO DE CULPABILIDAD: ESTADO DE LA CUESTIÓN*
}

\section{Claudia Marcela Cárdenas Aravena*}

RESUMEN: Se entrega una visión en perspectiva de la actual situación del principio de culpabilidad en la dogmática del derecho continental. Se comienza entregando una noción y revisando los aspectos fundamentales del principio. Se explica a continuación la relación entre el principio de culpabilidad y el concepto de culpabilidad, para luego revisar las principales tendencias en la discusión en torno al último. Por último, el trabajo se ocupa de lo que se ha dado en denominar la crisis del principio de culpabilidad, terminando con una reseña de la conclusión mayoritaria en cuanto a la necesidad de conservarlo.

Palabras ClaVE: Principio de culpabilidad - Concepto de culpabilidad - Coculpabilidad - Infidelidad al derecho - Abolición del principio de culpabilidad.

\section{THE CULPABILITY PRINCIPLE: CURRENT STATUS OF THE MATTER}

ABSTRACT: The article provides a perspective look of the current situation of the culpability principle in the Civil Law doctrine. It begins setting a notion and reviewing the fundamental aspects of the principle. It then explains the relationship between the culpability principle and the concept of culpability, in order to review the main trends in the discussion of the latter. Finally, the paper deals with the so called crisis of the culpability principle, to end with a summary of the majority's conclusion regarding the need to preserve it.

Este trabajo cuenta con el patrocinio de FONDECYT (proyecto No 1060410) y se basa en la ponencia presentada por la autora en las Primeras Jornadas Interdisciplinarias de Derecho de la Facultad de Derecho de la Universidad de Talca, "Los Principios Generales del Derecho", donde participó en el panel de Criminología y Derecho Penal: "Principios Cardinales del Derecho Penal. Un Estado de la Cuestión".

. Licenciada en Ciencias Jurídicas y Sociales de la Universidad de Chile, donde trabaja actualmente. Magíster y Doctor en Derecho de la Universidad Humboldt (Berlín). Correo electrónico: cardenascl@yahoo.de

Fecha de recepción: 17 de septiembre de 2008.

Fecha de aceptación: 28 de diciembre de 2008. 
KEY WORDS: Culpability principle - culpability concept - Co-culpability - Law infidelity - Abolition of the culpability principle.

\section{INTRODUCCIÓN}

Cabe delimitar, ante todo, el objeto de este trabajo. Se pretende con él dar resumida cuenta de los principales aspectos en la discusión actual acerca del principio de culpabilidad penal en la familia jurídica del derecho continental.

No parece adecuado referir aquí a la evolución histórica del principio, el que aparece suficientemente tratado en otros textos ${ }^{1}$. Baste con seńalar que este principio, al que hoy referimos entre los cardinales del derecho penal, no le es connatural. En efecto, por muchos siglos existió un derecho penal ignorante de un concepto de culpabilidad como lo entendemos hoy, según el cual derechamente se castigó en base a responsabilidad objetiva, lo que contraría al principio de culpabilidad en la concepción actualmente predominante. Asimismo, otras familias jurídicas tampoco conocen el principio de culpabilidad en el sentido que se le dará en el presente trabajo, de ahí lo relevante de esta delimitación inicial.

En lo sucesivo se presentarán, en primer lugar, algunos aspectos fundamentales del principio de culpabilidad, para adentrarnos luego en el principal punto actual de la discusión, cual es el concepto de culpabilidad que ha de otorgarle contenido al principio de culpabilidad. Por último, se reseñará la denominada crisis del principio de culpabilidad, dando cuenta en todo caso de la conclusión mayoritaria de la doctrina en cuanto a mantenerlo.

Por todos, Kaufmann, Arthur (1976) Das Schuldprinzip. Eine Strafrechtliche-rechtsphilosophische Untersuchung. Heidelberg: Carl Winter-Universitätsverlag; sin perjuicio de ArTEAGA, Alberto (1975) La culpabilidad en la teoria del hecho punible. Caracas: Universidad Central de Venezuela, 1975, 195 pp.; Bustos Ramírez, Juan José (2007) Obras Completas. Derecho Penal Parte General. Tomo I. Segunda edición. Santiago de Chile: Ediciones Jurídicas de Santiago, p. 703 y ss.; Cury UrzúA, Enrique (2005) Derecho Penal: Parte General. Tercera edición. Santiago de Chile: Ediciones Universidad Católica de Chile, p. 392 y ss.; FernánDez, Gonzalo (1995) Culpabilidad y Teoría del Delito. Buenos Aires: B de F, p. 137 y ss. Especialmente acucioso, en su particular enfoque, Melendo Pardos, Mariano (2002) El concepto material de culpabilidad y el principio de inexigibilidad: Sobre el nacimiento y evolución de las concepciones normativas. Granada: Editorial Comares, 636 pp.; también Roxin, Claus (2006). Strafrecht: Allgemeiner Teil. Band I. Grundlagen, Der Aufbau der Verbrechenslehre. Tomo I, Cuarta edición completamente revisada. Muenchen: Verlag C.H. Beck, p. 855 y ss.; Parma, Carlos (1997). Culpabilidad, lineamientos para su estudio. Mendoza: Ediciones jurídicas Cuyo, p. 21 y ss.; Soler, Sebastián (1962). "Culpabilidad real y culpabilidad presunta”. Anuario de Derecho Penal y Ciencias Penales, pp. 477-505; Villareal Palos, Arturo (1994). Culpabilidad y Pena. México: Editorial Porrúa S.A., p. 2 y ss. 


\section{ASPECTOS FUNDAMENTALES DEL PRINCIPIO DE CULPABILIDAD}

\section{Noción del principio de culpabilidad}

Durante los últimos siglos el principio de culpabilidad (nulla poena sine culpa) ha constituido para la doctrina mayoritaria en el ámbito jurídico del derecho continental ${ }^{2}$ un límite al ius puniendi, tanto a nivel de creación como de aplicación de normas penales, y lo es en un doble sentido. Por una parte, conforme al principio de culpabilidad, la culpabilidad constituye un requisito necesario para que pueda aplicarse una sanción penal. De esta premisa se sigue una proscripción de la posibilidad de imponer sanciones penales basándose en criterios de responsabilidad meramente objetiva, en la sola peligrosidad del sujeto u otras características personales; debe poder responsabilizarse a la persona por su hecho. De otro lado, el principio de culpabilidad también limita al ius puniendi en cuanto conforme a él no basta con que se determine la existencia de ciertos estándares mínimos de culpabilidad para que el Estado sea libre de aplicar cualquier pena, sino que la pena legítimamente aplicable al delito tiene que ser proporcional a la culpabilidad del sujeto ${ }^{3}$. En síntesis, el principio de culpabilidad significa que no hay pena sin culpabilidad y que la pena no puede sobrepasar la medida de la culpabilidad.

\section{Reconocimiento positivo del principio de culpabilidad}

En nuestro sistema jurídico no existe un reconocimiento expreso del principio de culpabilidad en cuanto tal. En el derecho comparado ha sido en no pocas ocasiones la jurisprudencia la que ha sostenido el rango constitucional del principio, a falta de norma expresa en tal sentido. Así ha sucedido en Alemania, Italia y España. Profusamente citada ha sido en particular la sentencia del Tribunal Constitucional Federal alemán en que se señala que "al principio de culpabilidad le corresponde un rango constitucional. Su fundamento está en el mismo principio del Estado de

Por todos, Bacigalupo Zapater, Enrique (2005) Derecho Penal y el Estado de Derecho. Santiago de Chile: Editorial Jurídica de Chile, p. 112. Este consenso no obsta a que ciertos autores observen que el respeto a esta garantía puede ser soslayado en los casos en que la reacción penal no consiste en una pena, sino en una medida de seguridad. Por todos, HasSEMER, Winfried (1983) Alternativen zum Schuldprinzip? En Baumgarten, Hans Michael/ Eser, Albin (editores) Schuld und Verantwortung. Tuebingen: J.C.B. Mohr (Paul Siebeck), pp. 89-107, p. 89 y ss.; Jescheck, Hans Heinrich/ Weigend, Thomas (2002) Tratado de Derecho Penal. Parte general. Trad. Olmedo Cardenete, Miguel. Granada: Comares, p. 24.

3 En palabras de Jescheck / Weigend: "Del principio de culpabilidad se deduce, de un lado, que la pena presupone siempre la culpabilidad, de modo de que quien actúa sin ella no puede ser castigado (exclusión de la responsabilidad por el resultado); y, del otro, que la pena no puede sobrepasar la medida de la culpabilidad (determinación de la pena en el marco del límite superior de la culpabilidad)." Jescheck/ Weigend (2002) 24. 
Derecho", en relación con la dignidad humana, ya que la culpabilidad no sería sino un corolario de la dignidad humana ${ }^{4}$.

En Chile, habida cuenta de que nuestra Constitución contiene normas análogas a las que entran en juego en Alemania y España, podría aventurarse una interpretación en el mismo sentido. Sin embargo, si bien el tema ha sido abordado ${ }^{5}$, falta todavía una mayor elaboración sobre el punto, como apunta Soto ${ }^{6}$.

Los pactos internacionales de derechos humanos establecen como garantía para las personas la necesidad de que se deba probar su culpabilidad para que sea legítimo imponerles una pena estatal. Cabe destacar, eso sí, que la voz "culpabilidad" suele utilizarse en las convenciones en el sentido de responsabilidad. Entre los tratados internacionales más relevantes en la materia, los siguientes prohíben que la responsabilidad penal -uno de cuyos requisitos según la doctrina dominante es la culpabilidad- pueda presumirse: Convención Interamericana de Derechos Humanos, artículo 8.2.7, Pacto Internacional de Derechos Civiles y Políticos artículo 14.2. ${ }^{8}$, Convenio Europeo para la Protección de los Derechos Humanos y de las Libertades Fundamentales Artículo 6 No $2^{9}$. En la misma línea, nuestra Constitución Política establece la prohibición de presumir la responsabilidad penal (artículo 19 No 3 inciso 6 de la Constitución Política de Chile) ${ }^{10}$.

\section{Principio de culpabilidad y culpabilidad penal}

El contenido del principio de culpabilidad dependerá del concepto de culpabilidad que se siga. Como señala Arthur Kaufmann en su obra dedicada al principio de culpabilidad, "está en la naturaleza de estos

BVerfGE 20, 232, 331. Sobre el particular JaÉn VAllejo, Manuel (1999) Principios constitucionales y derecho penal moderno. Estudios sobre cuestiones de especial relevancia constitucional. Buenos Aires: Ad Hoc, p. 39; Bacigalupo Zapater, Enrique (2002) Justicia penal y derechos fundamentales. Barcelona: Marcial Pons, p. 101; Jescheck, Hans Heinrich (2003) "Evolución del concepto jurídico penal de culpabilidad en Alemania y Austria". Trad. Esquinas Valverde, Patricia. Revista electrónica de Ciencia Penal y Criminología. RECPC 05-01, p. $01: 2$.

En particular Náquira Rrveros, Jaime (1995) “Constitución Política y fundamento material del principio de culpabilidad". Revista Chilena de Derecho, vol. 22 N $^{\circ} 2$, pp. 189-200. Soto Pińeiro, Miguel (1999) "Una jurisprudencia histórica. Hacia el reconocimiento del principio de culpabilidad en el derecho penal chileno". Revista de Derecho de la Universidad Finis Terrae, ańo 3 n $^{\circ}$, pp. 233-253, p. 240 y ss.; asimismo Künsemüller Loebenfelder, Carlos (2000) "Principio de culpabilidad - culpabilidad. Notas sobre su evolución y 'crisis". Revista de Derecho, Criminología y Ciencias Penales N², pp. 169-182, pp. 172 y ss. "Toda persona inculpada de delito tiene derecho a que se presuma su inocencia mientras no se establezca legalmente su culpabilidad".

"Toda persona acusada de un delito tiene derecho a que se presuma su inocencia mientras no se pruebe su culpabilidad conforme a la ley".

9 "Toda persona acusada de una infracción se presume inocente hasta que su culpabilidad haya sido legalmente declarada".

"La ley no podrá presumir de derecho la responsabilidad penal". 
principios jurídicos elementales el ser muy generales y abstractos, lo que no significa que sean indeterminados y formales" 11 . En concreto, si bien el principio de culpabilidad se puede distinguir conceptualmente de la culpabilidad, una reseńa del estado de la cuestión en materia de principio de culpabilidad quedaría incompleta si se hiciese caso omiso al contenido del concepto de culpabilidad y a la discusión en torno a él, pues si no se sabe cuál es el contenido de la culpabilidad tampoco podrá saberse en qué casos una persona ha actuado culpablemente, ergo, en qué casos y en qué medida puede castigársele sin violentar el principio de culpabilidad. Por lo demás, es justamente la discusión en torno al concepto de culpabilidad el que ha llevado a lo que se ha dado en denominar la actual crisis del principio de culpabilidad.

No se puede estar en acuerdo o desacuerdo con que la culpabilidad sea fundamento y medida de la pena si no se está pensando en un concepto concreto de culpabilidad. Y la referencia es deliberadamente a "un concepto concreto", porque si bien puede distinguirse una corriente mayoritaria, el concepto de culpabilidad es una de las materias debatidas en la actual dogmática penal.

En suma, para saber si se respeta el principio de culpabilidad, o si hay alternativas posibles, es necesario saber qué se entiende por culpabilidad, ya que es precisamente el concepto de culpabilidad el que da significado concreto al principio de culpabilidad ${ }^{12}$.

\section{CONCEPTO DE CULPABILIDAD}

Con la categoría de la culpabilidad -que le da contenido al principio de culpabilidad-se trata de determinar por qué se ha de hacer responsable a una persona que ha llevado a cabo una conducta típica y antijurídica. Una vez determinada la existencia de un injusto penal, ha de establecerse una relación entre él y una persona determinada en términos de que la aplicación de la pena aparezca legitimada. El examen de culpabilidad implica un momento de reflexión sobre los sujetos activos del delito y sus circunstancias, que resuelve las cuestiones de la necesidad de imposición de la pena y su cuantía.

Los antecedentes de esta categoría dogmática se encuentran recién en Puffendorf (s. XVII), hablando ya Feuerbach (1799) de la culpabilidad como fundamento subjetivo general de la punibilidad. Binding es, en tanto, el autor más conocido por integrar a la culpabilidad como categoría

Kaufmann (1976) 15 (traducción de la autora).

De allí que de las obras consultadas acerca del principio de culpabilidad todas indefectiblemente dedican un considerable espacio al concepto de culpabilidad. Cfr., en la doctrina nacional, KüNSEMÜLLER (2000) 170 y ss. 
dentro de la teoría del delito (1872), si bien con un contenido distinto del que actualmente se le atribuye. Imperaba entonces una noción psicológica de culpabilidad (culpabilidad como relación psicológica entre la persona y el hecho punible). Luego, a partir de Frank ${ }^{13}$, surgieron las corrientes normativistas (culpabilidad como juicio de valor conforme a una norma), mayoritarias hoy en día.

Como primer concepto amplio, aunque formal, puede señalarse que "[1] a culpabilidad es el fundamento para poder responsabilizar personalmente al autor por la acción típica y antijurídica que ha cometido mediante una pena estatal" ${ }^{14}$. Se señalará a continuación en qué consiste este fundamento, de acuerdo a distintas corrientes.

\section{Contenido que la doctrina actualmente dominante predica de la culpabilidad}

En la actualidad, la mayoría de la doctrina chilena ${ }^{15}$ consiente -de acuerdo con la corriente predominante en el sistema jurídico continentalen que la culpabilidad es en esencia un juicio de reproche del que se hace acreedor quien, pudiendo actuar conforme a derecho, no lo hace.

Esta noción normativa de culpabilidad acarrea una serie de consecuencias, que gozan de amplio reconocimiento. Sin embargo, no ha estado exenta de críticas ni menos ha hecho que la discusión sobre el concepto de culpabilidad se estabilice al punto de no existir propuestas y desarrollos paralelos. Un breve esbozo de las consecuencias de esta noción de culpabilidad, sus principales críticas y desarrollos paralelos serán presentados a continuación.

FranK, Reinhard (1966). Estructura del concepto de culpabilidad. Trad. Soler, Sebastián. Santiago de Chile, Publicaciones del seminario de Derecho Penal. Universidad de Chile, 76 pp. JESCHECK (2003) 01: 1.

CURY (2005) 385 (reproche porque el sujeto actuó de manera típica y antijurídica no obstante en la situación concreta podía someterse a los mandatos y prohibiciones del derecho); Etcheberry Orthusteguy, Alfredo (2005) Derecho Penal. T. I. Reimpresión de la tercera edición. Santiago de Chile, Editorial Jurídica de Chile, p. 271; Garrido Montr, Mario (2007) Derecho Penal. T. 2. Reimpresión de la 4a edición. Santiago: Editorial Jurídica de Chile, p. 253; Politoff Lifschitz, Sergio/ Matus Acuńa, Jean Pierre/ Ramírez Guzmán, María Cecilia (2004) Lecciones de Derecho Penal Chileno: Parte General. Segunda edición actualizada. Santiago de Chile, Editorial Jurídica de Chile, p. 243 (reproche porque el sujeto podía obrar diversamente y optó por la conducta prohibida). Posiciones minoritarias defienden Bustos (2007) T. I, 707 y ss. También Bustos (2007) T. II, 435 y ss. y 521 y ss. Asimismo difieren Bullemore Gallardo, Vivian; Mackinnon Roehrs, John (2007) Curso de Derecho Penal. Segunda Edición, aumentada y actualizada. Santiago de Chile: LexisNexis, p. 109 y ss. 


\subsection{Consecuencias del principio de culpabilidad conforme al conteni- do que predominantemente se le da al concepto de culpabilidad}

La principal fuente de consenso en torno al principio de culpabilidad está en las consecuencias que la concepción actualmente mayoritaria de culpabilidad tiene en cuanto a limitar el ius puniendi estatal en un Estado de Derecho, a saber ${ }^{16}$ :

- Posibilita la imputación subjetiva ${ }^{17}$ : los delitos son concebidos como conductas de una persona, no como catástrofes naturales o sociales. Se posibilita entonces el juzgamiento de una persona por lo que hizo, no por lo que es.

- Excluye la fundamentación o agravación de la pena por el mero resultado, por el simple azar, y la aplicación de principio de versari in re illicita.

- Permite diferenciar grados de participación interna y tener un parámetro para aplicar la proporcionalidad de las consecuencias jurídicas.

Son estas las principales consecuencias -cada una de las cuales supone a su vez consecuencias más concretas- del concepto actualmente dominante de culpabilidad, que da contenido al principio de culpabilidad.

\subsection{Principales críticas a la noción dominante de culpabilidad}

Frente a la noción mayoritaria que se reseña supra (2.1.) existen planteamientos críticos. Dentro de sus heterogéneos planteamientos, pueden sistematizarse los que siguen como los principales:

a) Crítica al reproche como categoría ética (no jurídica)

Hay quienes estiman que la naturaleza de juicio de reproche que se predica de la culpabilidad la hace asimilarse más bien a una categoría meramente ética (no jurídica) ${ }^{18}$. Esa crítica puede contrarrestarse sin grandes esfuerzos. Para comprender que el juicio es de naturaleza normativojurídica basta con constatar que no se reprocha el haber obrado "bien" o "mal" a secas, sino haberlo hecho en disconformidad a los imperativos

\footnotetext{
16 La sistematización de las consecuencias del principio de culpabilidad aparece, con mayor o menor detalle, en varios autores. En su estructura se sigue principalmente a HASSEMER, Winfried (1999) Persona, mundo y responsabilidad. Bases para una teoría de la imputación en derecho penal. Trad. Muñoz Conde, Francisco/ Díaz Pita, María del Mar. Bogotá: Temis, p. 53.

17 Hassemer (1983) 93 y ss.

18 Por todos, Velásquez B., Fernando (1993). "La culpabilidad y el principio de culpabilidad". Revista Derecho y Ciencias Politicas, vol. 50, p. 283-310. p. 299.
} 
jurídico penales que resguardan bienes jurídicos fundamentales como ultima ratio ${ }^{19}$. Prueba de que el juicio no se desenvuelve en categorías abstractas y subjetivas de "bien" y "mal" es que en nuestro sistema las circunstancias eximentes de culpabilidad están señaladas en la ley, pudiendo dejar fuera muchas hipótesis en las que podría considerarse que una persona actuó éticamente bien, por lo que su conducta no sería éticamente reprochable. Entonces, si bien se considera a la culpabilidad como una categoría valorativa, la valoración no se realiza respecto de una norma puramente ética, sino que respecto de una norma jurídica, más específicamente jurídico-penal.

b) Crítica por cuanto la posición dominante implicaría presumir el libre albedrío

Se suele criticar que el reproche de culpabilidad supone el libre albedrío, que es una premisa que al día de hoy no ha podido comprobarse. Esta suposición iría en contra de la garantía de que la culpabilidad debe probarse y no puede presumirse. Se objeta que se reproche al sujeto por haber elegido libremente actuar de manera típica y antijurídica, aunque escape a lo posible que se pueda probar ante un tribunal que tal libertad existió. Se sostiene que, aun cuando se asuma la posibilidad abstracta de que exista el libre albedrío, sería imposible comprobar que el individuo concreto ha actuado libremente en la situación concreta ${ }^{20}$.

Cierto es que el reproche de culpabilidad supone que la persona a la que va destinado tiene alternativas de comportamiento. Sin perjuicio de lo anterior, vale la pena destacar que la imputación no requiere que se pruebe una capacidad general del individuo de actuar libremente, sino que basta una "cierta libertad", identificable con la capacidad de recibir mensajes normativos y adaptar su conducta a los mismos ${ }^{21}$. Aquí solo está en juego la capacidad de la persona para decidir actuar o no de manera típica y antijurídica. El criterio de imputación más aceptado es el "poder general para actuar de otro modo"22.

El asumir que una persona puede actuar de distintas maneras optando por alguna de ellas no constituye un cuerpo extrańo en nuestro sistema jurídico ${ }^{23}$. Al contrario, constituye su piedra angular y se basa en la experiencia del actuar humano. Desde el punto de vista probatorio, tal capacidad podría considerarse como exento de prueba por tratarse de un hecho

Por todos, Jescheck/ Weigend (2002) 448 y ss.

Por todos, Córdoba Roda, Juan (1977) Culpabilidad y Pena. Barcelona: Bosch, p. 35.

Carbonell Mateu, Juan Carlos (1999) Derecho Penal: concepto y principios constitucionales, $3^{\text {a }}$ edición. Valencia: Tirant lo Blanch, pp. 218.

HASSEMER (1999) 52.

Kaufmann (1976) 437 y ss.; Jescheck (2003) 01:9 y ss.; Náquira (1995). 
notorio, ya que entra naturalmente en el conocimiento, en la cultura o en la información normal de los individuos.

De cualquier modo, frente a esta crítica, se buscó evadir la necesidad de la prueba de que la persona en concreto ha actuado libremente, haciendo bastar - para que una persona sea considerada culpable- que al hombre medio en tales circunstancias le hubiese sido posible actuar libremente ${ }^{24}$. Empero, esta suerte de solución a un problema dio lugar a otra crítica, que a continuación se reseña.

\section{c) Crítica al parangón del hombre medio}

Este reparo se basa en el hecho de que la doctrina dominante toma como parangón de la capacidad de obrar de otro modo al hombre medio en las circunstancias dadas ${ }^{25}$. Hay sectores de la academia que estiman que esta es una falla grave en el sistema, pues como consecuencia de este sistema de atribución de responsabilidad se podría aplicar sanciones penales (que implican restricción o privación de derechos fundamentales) a una persona concreta, en circunstancias de que el examen de culpabilidad no se realiza teniendo como parangón a esa persona, sino a un hombre medio. La gravedad del reparo es expresada por Mera, en el ámbito de la doctrina nacional, como sigue: "el baremo del hombre medio constituye, en los casos en que se formule el reproche de la culpabilidad a quien está por debajo de esa medida, una presunción de derecho de culpabilidad" 26 . De manera análoga argumentan Bustos y Hormazábal $^{27}$, por una parte, y Zaffaroni, Aliaga y Slokar ${ }^{28}$, por otra. Todos ellos destacan que el reproche no ha de dirigirse contra un ser abstracto dotado de libre albedrío y con una racionalidad homogénea, sino contra un hombre concreto en una sociedad desigual y discriminatoria. Postulan incluso que al momento de aplicar una pena no ha de mirarse solamente la responsabilidad individual de la persona, sino también la responsabilidad social por la conducta. Lo

\footnotetext{
KaUfManN (1976) 439.
}

KaUfMANN (1976) 439.

Mera Figueroa, Jorge Alberto (2005). Derechos Humanos en el Derecho Penal chileno. Reimpresión de la primera edición. Santiago de Chile: LexisNexis, p. 181 y ss. Para evitar una excesiva recarga en la labor jurisdiccional o una racha de impunidad, Mera propone que la presunción contenida en el artículo 1 inciso 2 del Código Penal se aplique para presumir que la persona pudo actuar de otro modo. Vale decir, se aplicaría igualmente el criterio del hombre medio, pero se admitiría prueba en contrario. Comparte esta crítica, en la doctrina nacional, Künsemüller Loebenfelder, Carlos (2001) Culpabilidad y Pena, Santiago de Chile: Editorial Jurídica de Chile, 2001, p. 201.

27 Bustos Ramírez, Juan José; Hormazábal Malarée, Hernán (2004). Nuevo Sistema de Derecho Penal. Madrid: Trotta, p. 126 y s.

28 Zaffaroni, Eugenio Raúl; Aliaga, Alejandro; Slokar, Alejandro (2005) Manual de Derecho Penal: parte general. Segunda reimpresión corregida. Buenos Aires: Ediar, p. 510 y ss. 
que en doctrina se ha dado por denominar coculpabilidad ${ }^{29}$ correspondería a un desarrollo que tiene origen en esta crítica.

\section{Propuestas y desarrollos paralelos más importantes}

Un esfuerzo por sistematizar las variadas propuestas de la doctrina ${ }^{30}$, nos detendremos en los postulados de la coculpabilidad (2.2.1.), de la culpabilidad como falta de fidelidad al derecho que afecta la confianza en la norma (2.2.2) y de la culpabilidad como actuar injusto a pesar de la posibilidad de ser alcanzado por la norma, que en todo caso no basta para predicar que exista responsabilidad (2.2.3.).

\subsection{Coculpabilidad ${ }^{31}$}

Esta corriente, si bien tiene sus orígenes en una crítica a la posición dominante en materia de culpabilidad ${ }^{32}$, se ha desarrollado como un planteamiento independiente de ella, pues propone que el examen de culpabilidad salga del ámbito en que solo es relevante el individuo, para incorporar también a la sociedad dentro del análisis.

No se trata entonces solamente del reproche al autor del injusto, sino también de la responsabilidad del Estado titular de un poder punitivo que se dirige a los grupos sociales cuya mayor vulnerabilidad no le es ajena.

Entre los autores chilenos, Bustos plantea la necesidad de reformular el contenido de la culpabilidad, habida consideración de la revolución jurídica que ha importado el deber de respeto y garantía de los derechos humanos que los Estados han asumido como deber jurídico desde la segunda mitad del s. XX ${ }^{33}$. Como toda persona tiene derechos, tiene también responsabilidad, como necesaria contrapartida. Siendo el Estado el responsable de respetar y garantizar esos derechos, corresponde discutir "qué le puede exigir al Estado una persona dada en una circunstancia dada" 34 .

Quienes sustentan este planteamiento discurren como sigue: si el Estado no ha cumplido con su obligación de dar a todas las personas acceso a ciertos bienes básicos, mal puede exigir a quienes les ha fallado el cumplimiento de sus normas sancionando penalmente a los infractores. El problema de la culpabilidad deriva entonces en determinar si el Estado está legitimado para exigir, a una persona en concreto, que responda por

Infra, 2.2.1.

Para otra sistematización, VeLÁsQuez (1993) 299 y ss., Bustos (2007) T. I, 78 y ss.

Parma (1997) 75 y ss.; Zaffaroni/ Alitaga/ Slokar (2005) 509.

Supra, 2.1.

Bustos (2007) T. II, 435 ss.

Bustos (2007) T. II, 437. 
su hecho injusto ${ }^{35}$. Por lo tanto, según esta corriente, al analizar cada caso penal concreto, el juez ha de considerar todas las circunstancias del individuo, en especial las que dicen relación con su oportunidad de acceso a bienes naturales y sociales, ya que solo así se cumpliría con la prohibición de presumir la capacidad de culpabilidad ${ }^{36}$.

Esta corriente de pensamiento aparece asociada a la criminología crítica de las últimas décadas del s. XX, que busca las raíces del fenómeno criminal utilizando un enfoque macrosociológico, estudiando e interpretando la influencia del funcionamiento de las estructuras sociales -entre ellas la aplicación de las normas penales- en las conductas desviadas que se consideran delito.

Cabe destacar que varios Códigos Penales de América Latina contienen disposiciones que se han considerado manifestaciones de este planteamiento. Así, el artículo 68 del Código Penal colombiano considera como atenuante a la indigencia ${ }^{37}$ y como agravante a la buena posición económica ${ }^{38}$. También se encuentran referencias en el Código Penal boliviano $^{39}$, en el ecuatoriano ${ }^{40}$, en el mexicano ${ }^{41}$ y en el argentino ${ }^{42}$.

Bustos (2007) T. II, 438; Bustos (2007) T. I, 718 y ss. También Hassemer (1999) 51.

Bustos / Hormazábal (2004) 125: "Para la teoría dogmática tradicional el problema de la responsabilidad del sujeto simplemente se reduce a una cuestión de la persona [...]. Ello trae como consecuencia la cosificación de la persona, en definitiva, que se la vea completamente despersonalizada $[\ldots]$ ".

Artículo 55: "Circunstancias de menor punibilidad. 8. La indigencia o la falta de ilustración, en cuanto hayan influido en la ejecución de la conducta punible". [...] Artículo 56: "El que realice la conducta punible bajo la influencia de profundas situaciones de marginalidad, ignorancia o pobreza extremas, en cuanto hayan influido directamente en la ejecución de la conducta punible y no tengan la entidad suficiente para excluir la responsabilidad, incurrirá en pena no mayor de la mitad del máximo, ni menor de la sexta parte del mínimo de la señalada en la respectiva disposición." [http://www.secretariasenado.gov.co/leyes/L0599000. HTM, consultado el 8 de marzo de 2008].

Artículo 58: “Circunstancias de mayor punibilidad. [...] 9. La posición distinguida que el sentenciado ocupe en la sociedad, por su cargo, posición económica, ilustración, poder, oficio o ministerio." [http://www.secretariasenado.gov.co/leyes/L0599000.HTM, consultado el 8 de marzo de 2008].

3 Artículo 38. [http://www.oas.org/juridico/spanish/gapeca_sp_docs_bol1.pdf, consultado el 8 de marzo de 2008].

Artículo 29: "Son circunstancias atenuantes [...] 110.- En los delitos contra la propiedad, cuando la indigencia, la numerosa familia, o la falta de trabajo han colocado al delincuente en una situación excepcional; o cuando una calamidad pública le hizo muy difícil conseguir honradamente los medios de subsistencia, en la época en que cometió la infracción". [http://www.oas.org/Juridico/mla/sp/ecu/sp_ecu-int-text-cp.pdf, consultado el 8 de marzo de 2008].

Artículo 52: "El juez fijará las penas [...] teniendo en cuenta: [...] V.- La edad, la educación, la ilustración, las costumbres, las condiciones sociales y económicas del sujeto, así como los motivos que lo impulsaron o determinaron a delinquir." [http://www.diputados.gob.mx/ LeyesBiblio/pdf/9.pdf, consultado el 8 de marzo de 2008].

Artículo 41: “[S]e tendrá en cuenta: [...] 2 20. La edad, la educación, las costumbres y la conducta precedente del sujeto, la calidad de los motivos que lo determinaron a delinquir, especialmente la miseria o la dificultad de ganarse el sustento propio necesario y el de los suyos, 
Como representantes de esta tendencia encontramos a Eugenio Raúl Zaffaroni, Alejandro Aliaga y Alejandro Slokar ${ }^{43}$, además de Juan Bustos ${ }^{44}$ y Hernán Hormazábal ${ }^{45}$. Como asevera este último, para esta corriente de pensamiento " $[\mathrm{n}] \mathrm{o}$ es la persona la que tiene que demostrar que no estaba en condiciones de cumplir con la norma, sino el Estado el que tiene que demostrar que a esa persona concreta le podía exigir un comportamiento conforme a la norma" 46 .

\subsection{Culpabilidad como falta de fidelidad al derecho que afecta la confianza en la norma}

Gran revuelo ha causado en la doctrina la propuesta del catedrático alemán Günther Jakobs, para quien hay culpabilidad cuando no existe una disposición a motivarse por la norma correspondiente -lo que constituye una falta de fidelidad al Derecho, que queda de manifiesto en la conducta típica y antijurídica ${ }^{47}$ - y este déficit afecta la confianza en la norma. Así, una vez que se acredita la existencia de un injusto que evidencia la falta de fidelidad con el Derecho, el fundamento para responsabilizar al autor por la acción típica y antijurídica que ha cometido está definida en virtud de consideraciones político-criminales, con lo que se ingresa en el ámbito de la prevención general pura: se castiga si es necesario para resta-

la participación que haya tomado en el hecho, las reincidencias en que hubiera incurrido". [http://www.infoleg.gov.ar/infolegInternet/anexos/15000-19999/16546/texact.htm\#3, consultado el 8 de marzo de 2008.

43 Ellos desarrollan una variante que denominan culpabilidad por vulnerabilidad, que resumen como sigue: "En síntesis, puede afirmarse que la culpabilidad por vulnerabilidad no es una alternativa a la culpabilidad como reproche formalmente ético, sino un paso superador de esta, que -como todo proceso dialéctico- la conserva en sus síntesis. Afirmada la culpabilidad socialmente ética como culpabilidad pura por el hecho, conforma al ámbito de autodeterminación con que el sujeto pudo deliberar y seńalando conforme a ella un cierto grado de reproche, la culpabilidad por el esfuerzo del sujeto para alcanzar la situación concreta de vulnerabilidad se le opone, para contrarrestar su desconsideración de la selectividad y, en la medida que corresponda, se sintetiza una culpabilidad normativa penal que puede reducir el reproche por el acto, pero nunca ampliarlo." Zaffaroni/ Aliaga/ Slokar (2005) $515 \mathrm{y} \mathrm{s.}$ A saber, Bustos (2007) T. I, 716; Bustos (2007) T. II, 439.

Bustos / Hormazábal (2004) 125 y ss.

Hormazábal Malarée, Hernán (2005) "Una necesaria revisión del concepto de culpabilidad". Revista de Derecho. Universidad Austral de Chile, vol.18, No 2, pp. 167-185, p. 179 y ss. En p. 185: "El Estado no está legitimado de modo general para exigir responsabilidad, sino que debe legitimarse en cada caso respecto de cada individuo en concreto. Esta legitimación debe entrar a considerar la forma en que se han distribuido los bienes sociales y la responsabilidad que pueda tener en una distribución desigual de estos respecto del individuo en concreto". "La responsabilidad así planteada, si se llega a establecer, será una corresponsabilidad de la persona y del Estado". p. 392. 
blecer la confianza en la norma ${ }^{48}$. A la sociedad se le devolvería la convicción de que la conducta no es deseable mediante la pena.

Este concepto de culpabilidad está inserto en un sistema en el que el fin del derecho penal es garantizar la vigencia de la norma, donde el sujeto activo del injusto sirve al sistema para hacer conocida la norma penal, mostrar la capacidad del Estado para garantizar su cumplimiento y reafirmar su vigencia.

En síntesis, para imputar al sujeto, respecto de la persona basta con que esta haya llevado a cabo una conducta típica y antijurídica. Ocurrido esto, la mirada no se vuelca ya al individuo para determinar si tal conducta ha de ser punible, sino a la sociedad, para ver si esa conducta ha afectado su confianza en la norma. Si lo ha hecho, la persona que ha incurrido en la conducta que ha provocado tal efecto es considerada culpable. Es, en cierta forma, una responsabilidad por el resultado de haber afectado la confianza en la norma.

Se critica ${ }^{49}$ que un principio de culpabilidad impregnado por este concepto de culpabilidad no sirve efectivamente a la limitación del ius puniendi estatal ${ }^{50}$, pues se basa precisamente en la necesidad del mismo Estado de mantener la confianza en el sistema, y por lo tanto no tendrá las consecuencias que tiene conforme a la concepción actualmente dominante de culpabilidad. Este concepto de culpabilidad tiende a aceptar la instrumentalización de la persona ${ }^{51}$, atentando con ello en contra de su dignidad, que es objeto de protección jurídica tanto en la Constitución Política como en los tratados internacionales vigentes ${ }^{52}$.

\subsection{Culpabilidad como actuar injusto a pesar de la capacidad de ser alcanzado por la norma}

En este punto será revisada la propuesta de Roxin, que se caracteriza por conciliar en cierta medida la noción de culpabilidad como reproche

Al respecto Кıм, Young-Whan (1987). Zur Fragwuerdigkeit und Notwendigkeit des Strafrechtlichen Schulprinzips: Ein Versuch zur Rekonstruktion der jüngsten Diskussion zu, Schuld und Prävention". Ebelsbach: Verlag Rolf Gremer, 143 pp.

49 El apartado 3. profundiza algo más en las críticas.

50 Roxin (2006) 866 y s.

51 Jakobs hace hincapié en que él no se propone la instrumentalización, sino que solo pone de relieve la instrumentalización existente. JAKовS (1997) 387.

52 Art. 1.1 de la Constitución Política de Chile: "Las personas nacen libres e iguales en dignidad y derechos". El inciso cuarto agrega: "El Estado está al servicio de la persona humana y su finalidad es promover el bien común, para lo cual debe contribuir a crear las condiciones sociales que permitan a todos y a cada uno de los integrantes de la comunidad nacional su mayor realización espiritual y material posible, con pleno respeto a los derechos y garantías que esta Constitución establece". En el Preámbulo del Pacto Internacional de Derechos Civiles y Políticos, se señala que "...estos derechos se derivan de la dignidad inherente a la persona humana". Convención Interamericana sobre Derechos Humanos, art. 11: "Toda persona tiene derecho al respeto de su honra y al reconocimiento de su dignidad". 
con las tendencias funcionalistas. Para este autor, el sujeto actúa de manera culpable si, en la situación concreta en la que se encuentra, podía ser alcanzado por la capacidad de motivación de la norma. Para poder declarar culpable a una persona habría que probar entonces que una actuación conforme a la norma le era posible al sujeto desde un punto de vista psíquico. Roxin deja de manifiesto que pretende no basarse en el libre albedrío, categoría indemostrable, sino que en la capacidad psíquica de dirigir el actuar que le está dada a los adultos sanos en la mayoría de las circunstancias.

Se trata al sujeto como si fuese libre, pues de lo contrario el sistema jurídico en su conjunto no podría operar. Se considera que esta capacidad de dirigir el propio comportamiento está empíricamente comprobada y es, a diferencia del libre albedrío en términos absolutos, demostrable ${ }^{53}$. Como consecuencia de lo anterior, se asume que la conducta es libre siempre que no haya sido fruto de coacción o acaso, sino expresión de las preferencias de quien actúa.

Con todo, Roxin no identifica a la culpabilidad con la responsabilidad. Para ser considerado responsable se requeriría, adicionalmente a la culpabilidad, que la reacción penal sea necesaria desde un punto de vista preventivo. Si no lo es, no sería legítimo aplicarla, aun cuando la persona fuese culpable $e^{54}$. Si bien reconoce el avance que significó la teoría normativa de la culpabilidad al superar categorías meramente psicológicas, estima que el problema no solamente consiste en si al sujeto es posible reprocharle el hecho, con lo que se sitúa dentro de las corrientes normativistas $^{55}$, sino que también hay que tener en consideración si es necesario hacerlo responsable desde el punto de vista jurídico penal ${ }^{56}$.

Con ello, Roxin sostiene que en virtud del principio de culpabilidad se ha de limitar la facultad de castigar aun en los casos en que una pena más gravosa fuese útil a los fines de prevención general o aseguramiento de la sociedad ${ }^{57}$.

Roxin (2006) 868 y ss.

Roxin (2006) 852 ss.

Roxin sistematiza las que considera las cinco variantes más significativas del normativismo: a) la culpabilidad como "poder actuar de otro modo"; b) la culpabilidad como convicción o actitud (Gesinnung) contraria a derecho (Medina lo traduce como "actitud interna jurídicamente desaprobada". Medina Jara, Rodrigo (2006). Manual de Derecho Penal. Reimpresión de la primera edición. Santiago de Chile: LexisNexis, p. 287); c) la culpabilidad como deber de hacerse responsable por el propio carácter; d) la culpabilidad como atribución desde necesidades de prevención general y por último e) la culpabilidad como actuar injusto a pesar de la capacidad de ser alcanzado por la norma. Roxin (2006) 860 y ss.

A análoga conclusión llega Bacigalupo (2002) 117.

Roxin (2006) 92. Urge confrontar este "deber ser" con la masiva aceptación y aplicación de la agravante de reincidencia, en que la pena se aumenta no por la culpabilidad por el hecho, sino bien sea por la conducción de vida, bien sea por un pronóstico futuro de peligrosidad que indica que más vale tener al sujeto inocuizado. Al respecto Zaffaroni/ Aliaga/ SLOKAR 


\section{La denominada crisis del principio de culpabilidad ¿̨es necesario conservarlo?}

Varios autores se refieren a la crisis del principio de culpabilidad ${ }^{58}$. El estado de crisis, sin embargo, le es casi connatural, ya que el concepto de culpabilidad, que da contenido al principio, ha experimentado desde su aparición lo que podría denominarse una crisis permanente, lo que no significa otra cosa que el hecho de que ha estado en permanente evolución, acompańando de manera importante los vaivenes de la dogmática jurídico-penal ${ }^{59}$.

Con lo ya expresado respecto de la relación entre el principio de culpabilidad y el concepto de culpabilidad, quedará claro que quienes controvierten el principio de culpabilidad están en realidad en desacuerdo con el contenido que se le viene dando al concepto de culpabilidad ${ }^{60}$. No son necesarios grandes esfuerzos para constatar que al construir un sistema a partir de un concepto de culpabilidad distinto del actualmente dominante (como la coculpabilidad o la culpabilidad como afectación de la confianza en la norma) el contenido del principio de culpabilidad, sus consecuencias, serían distintas de las que hoy tenemos internalizadas como tales, sea por limitar más fuertemente al ius puniendi (coculpabilidad) o porque dejaría de ser un límite externo y por lo tanto real para él (afectación de la confianza en la norma). Eso significaría claramente la crisis del principio tal y como se lo entiende en la actualidad, sobre todo en cuanto a sus consecuencias.

Los autores contemporáneos que se refieren al principio de culpabilidad y a la necesidad de mantenerlo han dedicado sus mayores energías a defenderlo frente a la concepción funcionalista. Jakobs explica su posición respecto del principio de culpabilidad de acuerdo al contenido que hoy mayoritariamente se le atribuye razonando de la siguiente manera:

"la pena que es útil para la consecución de sus fines sociales, si no está limitada por el principio de la culpabilidad, trata como cosa a la

(2005) 507; y JaÉn Vallejo, Manuel (2006) Estudios Penales. Santiago de Chile: Lexis Nexis, p. 38 y ss.

58 En Chile, por todos, KüNSEMÜLLER (2000).

59 KÜNSEMÜLLER (2000).

60 KüNSEmüller (2000), p. 176: "Podría postularse que la 'crisis' de la culpabilidad (de una noción de ella) involucra necesariamente la 'crisis' del principio de culpabilidad, en cuanto ella (la categoría) es objeto y contenido del apotegma, hay una relación de 'contenido' y 'continente'." La crisis en realidad, dice el autor, no es ni del continente ni del contenido, sino de una determinada forma de entender la culpabilidad. Acerca de las historicidad de la noción de culpabilidad, KaUfManN (1976) 217 ss. 
persona que va a ser sometida a ella, pero la pena que se ve limitada por la culpabilidad de una manera más que marginal pierde su funcionalidad"61; y con ello, para el autor, su legitimidad. Deja de este modo de manifiesto que no cree que el principio de culpabilidad deba ser un límite inamovible para el ius puniendi, sino que por el contrario, su consideración "excesiva” podría incluso tornarlo ilegítimo. Así, se manifiesta abiertamente en contra del respeto irrestricto del principio de culpabilidad en el sentido que actualmente se le atribuye, con lo que cuestiona el principio de culpabilidad en su concepción actualmente mayoritaria abogando por los intereses de una política criminal eficaz.

No parece, sin embargo, que las diferencias en cuanto al contenido que ha de tener el principio de culpabilidad vayan a suscitar su crisis definitiva, al menos por el momento. En el entendido de que el derecho penal y en particular el principio de culpabilidad constituyen límites a la potestad de castigo estatal, predomina la opinión de que para la efectividad de esta función sus límites deben tener algún contenido no del todo disponible para el Estado según sus necesidades. Como señala Hassemer, tradicionalmente el principio de culpabilidad tiene la tarea de marcar los límites dentro de los cuales el delincuente puede ser sacrificado a los intereses preventivos de estabilización normativa, de su intimidación y tratamiento ${ }^{62}$. Aceptando que el derecho penal y la culpabilidad pretenden justificar la imputación de responsabilidad penal a una persona de una manera no arbitraria y que permita su control ${ }^{63}$, mayoritariamente se entiende que solo mediante la vinculación de la pena con la existencia de un reproche y de la gravedad de la pena aplicable con la gravedad del reproche parece posible evitar una instrumentalización de la persona que debe sufrir la pena ${ }^{64}$.

Las consecuencias del principio de culpabilidad conforme a la concepción dominante de culpabilidad aparecen entonces como irrenunciables para gran parte de la doctrina ${ }^{65}$. Al imaginarse un sistema sin principio de culpabilidad o con una aceptación solo formal de él ${ }^{66}$, se

61

62

63

64

65

66
JаKовS (1997) 366.

HASSEMER (1999) 53 y 62.

Sото (1999) 244.

Bacigalupo (2002) 114.

Hassemer (1983) 93 y ss.; Hassemer (1999) 53; Roxin, Claus (1992) Politica criminal y estructura del delito. Elementos del delito en base a la politica criminal. Trad. Bustos Ramírez, Juan José; Hormazábal Malarée, Hernán. Barcelona; PPU, p. 141: "[N]o se ha logrado hasta ahora encontrar una alternativa para el principio de culpabilidad con ayuda de los cuales (sic) pudiese determinarse de un mejor modo, en un Estado de Derecho, los presupuestos de las facultades de intervención estatal"; BaCigalupo (2002) 101 y ss.; CórDoba (1977) 38 y ss.; Hormazábal (2005) 172. Igualmente Zaffaroni / Aliaga / Slokar (2005) 503. En la doctrina nacional, Sото (1999).

En el régimen nacionalsocialista no se abandonó nominalmente la categoría, sino que se modificó su contenido: se abandonó la culpabilidad por el acto y pasó a ser determinante 
hace patente que este parece imprescindible como límite a la intervención estatal $^{67}$.

En general, si una vez realizado un injusto la pena está fundamentada por su necesidad, nada impide que se llegue a penas (o medidas) netamente inocuizadoras, pues el límite de la necesidad puede variar sin que en ello tenga influencia la persona concreta. Con ello, el individuo (sus derechos, de los que es titular en cuanto es persona y que el Estado debe garantizar) son puestos al servicio de un bien que se considera superior: la confianza en el sistema y la fidelidad ciudadana al Derecho, que se pretende afianzar mediante el castigo que persigue. Esto parece colisionar con normas fundamentales del mismo sistema que se pretende hacer prevalecer (por ejemplo, en Chile, el Estado está al servicio de la persona humana: de toda persona humana, no solamente de los obedientes).

Alternativas históricas al principio de culpabilidad como hoy mayoritariamente se entiende han sido la responsabilidad objetiva y el dejar la sanción penal vinculada exclusivamente a criterios de peligrosidad y utilidad. Según la constatación empírica estas opciones no han traído buenos dividendos a los derechos de las personas.

Por otra parte, desde la perspectiva del utilitarismo hay quienes argumentan que si el riesgo de sufrir una pena no va unido a una conducta que la persona puede evitar o decidir efectuar se aumentaría enormemente la inseguridad general de la población, por lo que suprimir el principio de culpabilidad tendría un costo social demasiado alto ${ }^{68}$.

\section{CONCLUSIONES}

El principio de culpabilidad, felizmente sintetizado en la fórmula "ninguna pena sin culpabilidad, pena solamente en la medida de la culpabilidad" 69 aun no teniendo consagración positiva expresa, es aceptado por la doctrina ampliamente mayoritaria, que sobre todo no está dispuesta a renunciar a las consecuencias limitadoras al ejercicio del ius

la culpabilidad por la conducción de vida o por el carácter: el juez emitía un juicio de presunción que recaía sobre el autor por contradecir la voluntad del pueblo. El hecho injusto se consideró solamente un síntoma de la voluntad criminal, la pena se basaba entonces en la peligrosidad por contrariar al sano entendimiento del pueblo alemán.

No se nos escapa que forma parte de la normalidad jurídica actual el que la reacción penal prescinda de la culpabilidad en la imposición de medidas de seguridad. Sobre el particular, Hassemer (1983) 89 y ss. Sobre la idea de que la culpabilidad solo sirve para etiquetar como "pena" la reacción penal, pero no la limita, pues igualmente si falta la culpabilidad el sistema penal responde mediante medidas de seguridad. KIM (1987) 16 y ss. garten, Hans Michael/ Eser, Albin (editores). Schuld und Verantwortung. Tuebingen: J.C.B. Mohr (Paul Siebeck), pp. 51-87, p. 70 y s. 
puniendi, que tiene el principio conforme a la posición actualmente mayoritaria de culpabilidad.

La ciencia penal ha invertido muchas energías en encontrar un concepto de culpabilidad exento de contradicciones, coherente con el desarrollo actual de las ciencias empíricas y sociales. Al día de hoy no parece haberse logrado la fórmula perfecta. Junto con la mayoritaria forma de entender a la culpabilidad como un juicio de reproche por no haber actuado conforme a la norma pudiendo hacerlo, han surgido una serie de otras posiciones, entre las que destacan la coculpabilidad, la funcionalista de Jakobs y la posición ecléctica de Roxin.

Así y todo, a pesar de la permanente pugna en torno al concepto de culpabilidad, abandonar el contenido y las características del principio de culpabilidad conforme a los conceptos mayoritariamente aceptados no parece aconsejable salvo que se lo reemplace por una noción que sirva igualmente de límite al ius puniendi y sea compatible con las normas fundamentales de nuestro sistema jurídico. Ante la alternativa de la responsabilidad penal objetiva o la responsabilidad penal por peligrosidad, parece mejor buscar alternativas que conserven al principio de culpabilidad como garantía para el ciudadano en un Estado de Derecho.

\section{BIBLIOGRAFÍA}

- Arteaga, Alberto (1975) La culpabilidad en la teoría del hecho punible. Caracas: Universidad Central de Venezuela, 1975.

- Bacigalupo Zapater, Enrique (2002) Justicia penal y derechos fundamentales. Barcelona: Marcial Pons.

(2005) Derecho Penal y el Estado de Derecho. Santiago de Chile: Editorial Jurídica de Chile.

- Bullemore Gallardo, Vivian; Mackinnon Roehrs, John (2007) Curso de Derecho Penal. Segunda Edición, aumentada y actualizada. Santiago de Chile: LexisNexis.

- Burkhardt, Bjoern (1983) "Utilitaristische Rechtfertigung des Schuldprinzips". En Baumgarten, Hans Michael/ Eser, Albin (editores). Schuld und Verantwortung. Tuebingen: J.C.B. Mohr (Paul Siebeck).

- Bustos Ramírez, Juan (2007) Obras Completas. Derecho Penal Parte General. Tomo I y II. Segunda edición. Santiago de Chile: Ediciones Jurídicas de Santiago.

- Bustos Ramírez, Juan José; Hormazábal Malarée, Hernán (2004). Nuevo Sistema de Derecho Penal. Madrid: Trotta,

- Carbonell Mateu, Juan Carlos (1999) Derecho Penal: concepto y principios constitucionales, $3^{\text {a }}$ edición. Valencia: Tirant lo Blanch.

- Córdoba Roda, Juan (1977) Culpabilidad y Pena. Barcelona: Bosch. 
- Cury Urzúa, Enrique (2005) Derecho Penal: Parte General. Tercera edición. Santiago de Chile: Ediciones Universidad Católica de Chile.

- Etcheberry Orthusteguy, Alfredo (2005) Derecho Penal. T. I. Reimpresión de la tercera edición. Santiago de Chile, Editorial Jurídica de Chile.

- Fernández, Gonzalo (1995) Culpabilidad y Teoría del Delito. Buenos Aires: B de F.

- Frank, Reinhard (1966). Estructura del concepto de culpabilidad. Trad. Soler, Sebastián. Santiago de Chile, Publicaciones del seminario de Derecho Penal. Universidad de Chile.

- Garrido Montt, Mario (2007) Derecho Penal. T. 2. Reimpresión de la $4^{a}$ edición. Santiago: Editorial Jurídica de Chile.

- Hassemer, Winfried (1983) Alternativen zum Schuldprinzip? En Baumgarten, Hans Michael/ Eser, Albin (editores) Schuld und Verantwortung. Tuebingen: J.C.B. Mohr (Paul Siebeck).

(1999) Persona, mundo y responsabilidad. Bases para una teoría de la imputación en derecho penal. Trad. Muńoz Conde, Francisco/ Díaz Pita, María del Mar. Bogotá: Temis.

- Hormazábal Malarée, Hernán (2005) "Una necesaria revisión del concepto de culpabilidad". Revista de Derecho. Universidad Austral de Chile, vol.18, No 2.

- JaÉn Vallejo, Manuel (1999) Principios constitucionales y derecho penal moderno. Estudios sobre cuestiones de especial relevancia constitucional. Buenos Aires: Ad Hoc.

(2006) Estudios Penales. Santiago de Chile: LexisNexis.

- Jakoвs, Günther (1997). Estudios de Derecho Penal. Trad. Peñaranda Ramos, Enrique/ Suárez González, Carlos J./ Cancio Meliá, Manuel. Madrid: Civitas.

- Jescheck, Hans Heinrich (2003) "Evolución del concepto jurídico penal de culpabilidad en Alemania y Austria”. Trad. Esquinas Valverde, Patricia. Revista electrónica de Ciencia Penal y Criminología. RECPC 05-01.

/ Weigend, Thomas (2002) Tratado de Derecho Penal. Parte general. Trad. Olmedo Cardenete, Miguel. Granada: Comares.

- Kaufmann, Arthur (1976) Das Schuldprinzip. Eine Strafrechtlicherechtsphilosophische Untersuchung. Heidelberg: Carl Winter-Universitätsverlag.

- Kim, Young-Whan (1987). Zur Fragwuerdigkeit und Notwendigkeit des Strafrechtlichen Schulprinzips: Ein Versuch zur Rekonstruktion der jüngsten Diskussion zu, Schuld und Prävention”. Ebelsbach: Verlag Rolf Gremer.

- Künsemüller Loebenfelder, Carlos (2000) "Principio de culpabilidad - culpabilidad. Notas sobre su evolución y "crisis". Revista de Derecho, Criminología y Ciencias Penales $\mathrm{N}^{\circ} 2$. 
(2001) Culpabilidad y Pena, Santiago de Chile: Editorial

Jurídica de Chile.

- Medina Jara, Rodrigo (2006). Manual de Derecho Penal. Reimpresión de la primera edición. Santiago de Chile: LexisNexis.

- Melendo Pardos, Mariano (2002) El concepto material de culpabilidad y el principio de inexigibilidad: Sobre el nacimiento y evolución de las concepciones normativas. Granada: Editorial Comares.

- Mera Figueroa, Jorge Alberto (2005). Derechos Humanos en el Derecho Penal chileno. Reimpresión de la primera edición. Santiago de Chile: LexisNexis.

- Náquira Riveros, Jaime (1995) "Constitución Política y fundamento material del principio de culpabilidad". Revista Chilena de Derecho, vol. $22 \mathrm{~N}^{\circ} 2$.

- Parma, Carlos (1997). Culpabilidad, lineamientos para su estudio. Mendoza: Ediciones jurídicas Cuyo.

- Politoff Lifschitz, Sergio/ Matus Acuña, Jean Pierre/ Ramírez Guzmán, María Cecilia (2004) Lecciones de Derecho Penal Chileno: Parte General. Segunda edición actualizada. Santiago de Chile, Editorial Jurídica de Chile.

- Roxin, Claus (1992) Politica criminal y estructura del delito. Elementos del delito en base a la politica criminal. Trad. Bustos Ramírez, Juan; Hormazábal Malarée, Hernán. Barcelona; PPU.

(2006). Strafrecht: Allgemeiner Teil. Band I. Grundlagen,

Der Aufbau der Verbrechenslehre. Tomo I, Cuarta edición completamente revisada. Muenchen: Verlag C.H. Beck.

- Soler, Sebastián (1962). "Culpabilidad real y culpabilidad presunta”. Anuario de Derecho Penal y Ciencias Penales.

- Soto Piñeiro, Miguel (1999) "Una jurisprudencia histórica. Hacia el reconocimiento del principio de culpabilidad en el derecho penal chileno". Revista de Derecho de la Universidad Finis Terrae, año 3 n$^{\circ} 3$.

- Velásquez B., Fernando (1993). "La culpabilidad y el principio de culpabilidad”. Revista Derecho y Ciencias Políticas, vol. 50.

- Villareal Palos, Arturo (1994). Culpabilidad y Pena. México: Editorial Porrúa S.A.

- Zaffaroni, Eugenio Raúl; Aliaga, Alejandro; Slokar, Alejandro (2005) Manual de Derecho Penal: parte general. Segunda reimpresión corregida. Buenos Aires: Ediar. 